\title{
Ceria nanoparticles boost activity of aged murine oocytes
}

\author{
NYa Spivak ${ }^{1}$, EA Shepel ${ }^{2}$, NM Zholobak ${ }^{1}$, AB Shcherbakov ${ }^{1}{ }^{*}$, GV Antonovitch $^{1}$, RI Yanchiy ${ }^{2}$, VK Ivanov YuD Tretyakoy $^{3,4}$ Yu $^{3,4}$ \\ ${ }^{1}$ Zabolotny Institute of Microbiology and Virology, NAS of Ukraine, Zabolotnogo str. 154, Kiev, D 03680, Ukraine \\ ${ }^{2}$ Bogomoletz Institute of Physiology, NAS of Ukraine, Bogomoletz str. 4, Kiev, 01024, Ukraine \\ ${ }^{3}$ Kurnakov Institute of General and Inorganic Chemistry, Russian Academy of Sciences, Leninskii pr. 31, Moscow, 119991, Russia \\ ${ }^{4}$ Department of Materials Science of Moscow State University, Lenin Hills, Moscow, 119991, Russia \\ * Corresponding author: carotene@mail.ru \\ Tel/fax.: +380-67-9865800
}

\begin{abstract}
Oocyte meiotic maturation and viability of follicular granulosa cells in young and old experimental Balb/C and CBA mice in the presence of ceria nanoparticles were studied. Treatment of old Balb/c mice with ceria nanoparticles for three days once a day (at a dose of $45 \mathrm{mg} / \mathrm{kg}$ ) leads to a positive effect on reproductive system. The number of oocytes in follicles increases and this effect is accompanied by an increase in the number of oocytes at metaphase I and metaphase II. The number of living granulosa cells increases, while percentage of the necrotic and apoptotic ones decreases relative to control group. Data obtained on CBA mice provided additional evidence for positive effect of ceria nanoparticles. Depending on the initial state of the reproductive system and dose of ceria nanoparticles the effectiveness of the treatment will vary. In case of old mice ceria nanoparticles protect ovarian cells against oxidative damage, working as anti-aging agent. The litter size in old mice treated with the CNs increases too.
\end{abstract}

Keywords: Ceria, Nanoparticle, Antioxidants, Oocyte meiotic maturation, Granulosa cell viability.

Citation: NYa Spivak et al. Ceria nanoparticles boost activity of aged murine oocytes. Nano Biomed. Eng. 2012, 4(4), 188-194. DOI: $10.5101 /$ nbe.v4i4.p188-194.

\section{Introduction}

Application of cerium compounds as components of pharmaceuticals is a common practice. In most cases active component is represented by water-soluble cerium (3+) salts (nitrate, chloride, sulphate and acetate), as well as by some insoluble compounds (stearate, oxalate) in the form of colloid solutions [1].

The mechanism the cerium compounds act on organism is still not quite clear. In some instances biological activity of cerium compounds can be explained by similar ionic radii of cerium $(3+)$ and calcium $(2+)$, which enables partial calcium substitution by cerium in a number of biomolecules and therefore-manifestation of various biological effects. Mineral salts of rare earth elements (including cerium) are used as feed additives of animals in China more than 40 years. Numerous Chinese reports describe that a small amount of these lanthanides in the diet can increase the body weight gain of pigs, cattle, sheep, chicken and egg production.

Information on biological activity of ceria (cerium dioxide, $\mathrm{CeO}_{2}$ ) is even much more fragmentary: until recently little attention was paid to this substance, since cerium dioxide is not soluble in water or biological fluids. However, the evidences for promising biomedical applications of ceria in nanocrystalline form were recently reported [2-5], for instance, UV-shielding property [6], antiviral activity of ceria colloids [7] etc.

An assumption was made that ceria nanoparticles (nanoceria, CNs) interaction with biological systems is based on two basic properties of this substance: low toxicity and high reducibility [5]. These factors determine activity of $\mathrm{CNs}$ in biological redox processes [8], especially in inactivation of reactive oxygen species (ROS), including free radicals that are formed inside living cells. Recently antioxidant action of CNs upon HT22 neuron cellular target [9] was also demonstrated, which suggest profitable use of CNs agains neurodegenerative diseases. In vivo studies show that nanoceria administration to mice reduces oxidative stress. Nanoceria may decrease ROS content, thereby suggesting that $\mathrm{CNs}$ may be a useful antioxidant treatment for oxidative stress in mice [10]. As aging processes are known to be associated with the development of oxidative stress [11], the question about possible influence of the 
CNs on the old animals has arisen. In our preliminary study of biological effects induced by $\mathrm{CeO}_{2}$ (2-5 $\mathrm{nm}$ ) in experimental animals, an unexpected positive influence upon sexual activity of old mice and recovered reproductive ability have been noted. Therefore we have decided to investigate the effect of $\mathrm{CNs}$ on oocyte meiotic maturation and viability of follicular granulosa cells in experimental animals.

\section{Experimental section.}

\subsection{Colloid solution of ceria nanoparticles.}

$0.1 \mathrm{M}$ colloid solutions of CNs stabilized by $0.1 \mathrm{M}$ ammonium citrate were synthesized as follows [12]: 3.73 $\mathrm{g}$ of cerium (III) chloride heptahydrate and $2.0 \mathrm{~g}$ of citric acid were dissolved in $20 \mathrm{~mL}$ of distilled water. Under continuous stirring this solution was added rapidly to aqueous ammonia solution prepared by mixing $10 \mathrm{~g}$ of concentrated ammonia solution (Sigma, USA) and 100 $\mathrm{mL}$ of distilled water. The resulting mixture was stirred for $5 \mathrm{~h}$, with further boiling aiming at producing $100 \mathrm{~mL}$ of $0.1 \mathrm{M}$ ceria sol.

Optical absorption spectra were recorded on an OceanOptics QE 65000 spectrometer using a one beam scheme. The radiation sources were a DH 2000 deuterium-halogen lamp and an HPX 2000 xenon lamp. Optical absorption spectra were further used to calculate the bandgap energy $\mathrm{Eg}$ of $\mathrm{CeO}_{2}$ nanoparticles.

The size of CNs was determined by transmission electron microscopy (TEM) on a Leo 912 AB Omega electron microscope at $100 \mathrm{kV}$ accelerating voltage.

The hydrodynamic diameter by the dynamic light scattering (DLS) method and zeta-potential of citratecoated $\mathrm{CeO}_{2}$ nanoparticles was measured on a Malvern Zetasizer Nano ZS analyzer. Before the measurements, the sol was diluted with distilled water.
Powder X-ray diffraction (XRD) analysis of ceria nanopowders prepared by sols centrifuging was carried out on a Rigaku D/MAX 2500 diffractometer $\left(\mathrm{CuK}_{\alpha}\right.$ radiation, instrumental broadening $\left.0.10 \pm 0.01^{\circ} 2 \theta\right)$. The goniometer rotation speed was $2^{\circ} 2 \theta / \mathrm{min}$. Crystallite size (D) of nanocrystalline ceria was calculated using Scherrer formula where coefficient of anisotropy was set to 1 . Line profiles for (111) and (200) reflections were fitted to pseudo-Voigt functions.

XRD has shown that the particles separated from the sol by centrifuging are single-phased and correspond to cubic $\mathrm{CeO} 2$. Analysis of diffraction peaks broadening indicates that synthesis method proposed allowed us to obtain ceria samples with crystallite size about $3 \mathrm{~nm}$.

According to TEM micrographs and electron diffraction data (Fig. 1) the sol consists of weakly aggregated $\mathrm{CNs}$ of nearly isotropic shape $2-5 \mathrm{~nm}$ in size. Dynamic light scattering data indicate that mean hydrodynamic diameter of $\mathrm{CeO} 2$ particles is $4.9 \mathrm{~nm}$. This is consistent with the TEM data and is evidence that the presence of a monomolecular (or submonomolecular) layer of citrate ions has no noticeable effect on the particle size. Zetapotential of CNs is negative $(-20 \mathrm{mV})$.

According to UV-Vis spectroscopy data, the bandgap for $\mathrm{CNs}$ is $3.5 \mathrm{eV}$. Upon long-term storage the bandgap of CNs stayed unchanged thus indicating that the particle size in ceria sols is constant.

\subsection{Animals. Isolation of oocytes and granulosa cells.}

Determination of oocyte meiotic maturation. Inbred strains Balb/c and CBA of laboratory mice were used, namely old female mice at the age of 9-10 months: Balb/ c (34-37 g) and CBA (25-28 g), as well as young female mice of the same lines (Balb/c, 22-23 g, and CBA, 16-20 g) that have recently reached sexual maturity (6-8 week

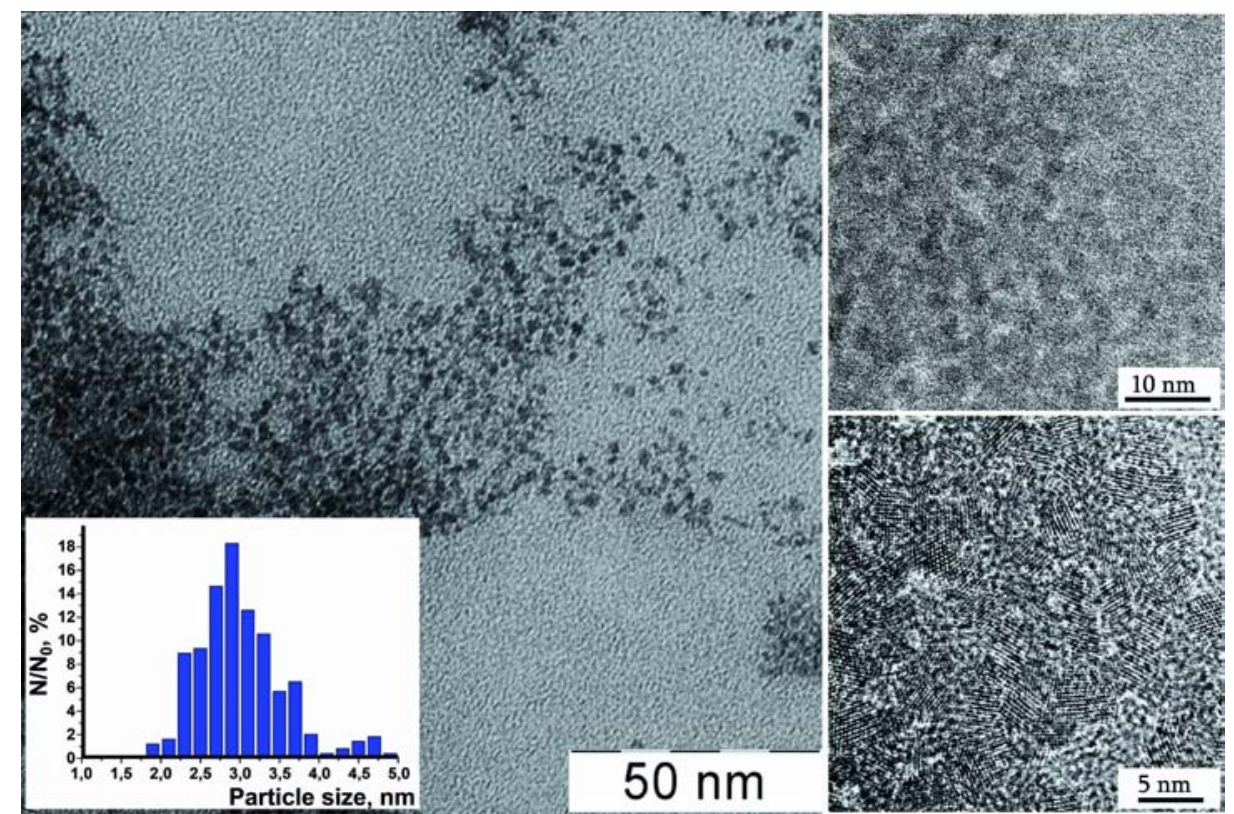

Fig. 1 TEM (scale bar of 50nm) and HRTEM (scale bar of $10 \mathrm{~nm}$ and $5 \mathrm{~nm}$ ) images of CNs in citrate-stabilized sol. Inset: particle size distribution according to TEM data. 
age). Animals were kept at standard conditions with ad libitum provision of adequate diet.

Follicles were separated from ovaries under stereoscopic microscope and pressed with $23 \mathrm{G}$ needle in Dulbecco's modified Eagle's medium (DMEM, Sigma, USA) to release cumulus-oocyte complexes (COCs) and granulosa cells. COCs were separated from other follicular cells without enzymes. Granulosa cells were sampled into sterile eppendorfs for further investigation of their viability.

COCs were cultured for $20 \mathrm{~h}$ in 4-well plates (Costar, USA) containing $500 \mu \mathrm{L}$ of DMEM with physiological $\mathrm{Ca}^{2+}$ concentration $(1,71 \mathrm{mM})$ and supplemented with HEPES (15 mM) (Sigma, USA), 5\% fetal bovine serum and antibiotics. Cells were kept at $37^{\circ} \mathrm{C}$ inside sterile box. The number of oocytes with germinal vesicle breakdown (metaphase I) was counted after $4 \mathrm{~h}$, while the number of oocytes forming the first polar body (metaphase II) was estimated by optical microscopy after $20 \mathrm{~h}$ (Fig. 2).

To distinguish between live, apoptotic, and necrotic granulosa cells supravital double staining was applied with Hoechst 33342 and propidium iodide dyes [13,14]. Propidium iodide can only enter cells with damaged membranes, staining their nuclei red. Hoechst dye 33342 can pass through intact membranes, causing green-blue
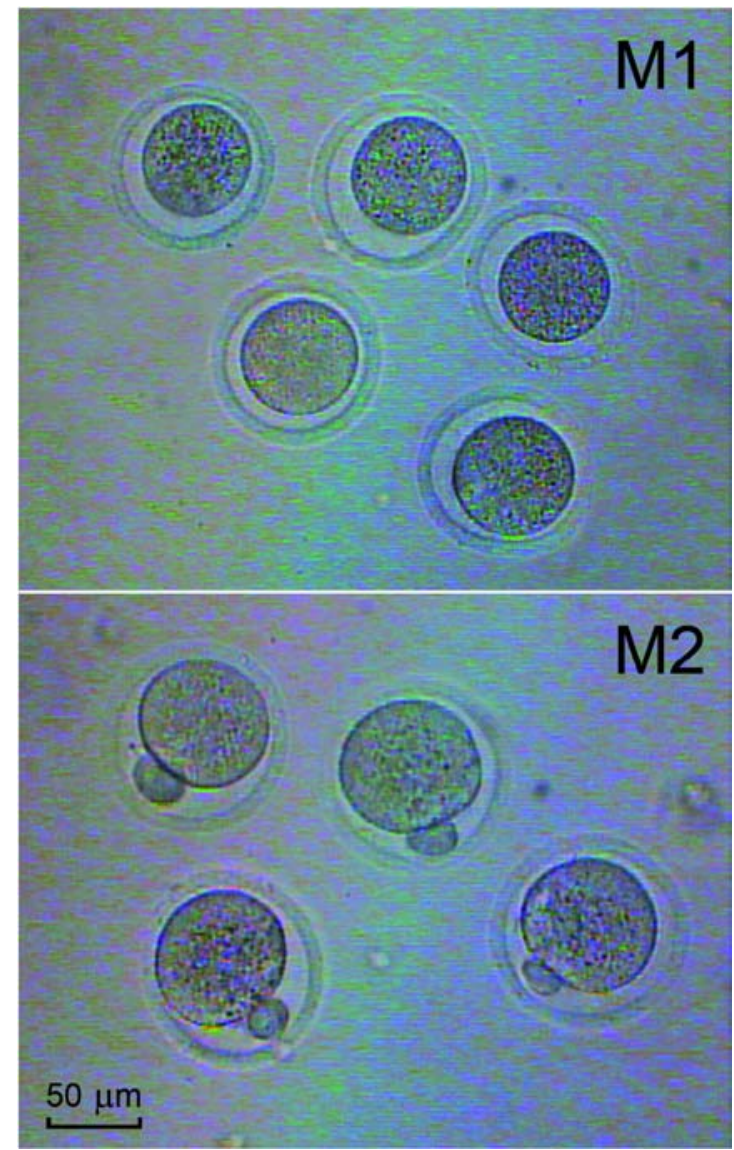

Fig. 2 In Vitro Oocyte Maturation. Light micrograph of oocytes at two stages of their development: M1-metaphase I oocyte (break down of the germinal vesicle after $4 \mathrm{~h}$ culture); M2-metaphase II oocyte (emission of the first polar body after $20 \mathrm{~h}$ of culture). Scale bar is $50 \mu \mathrm{m}$. color of living cells. Morphological characteristics of the nucleus, specific for apoptosis, can be detected after binding of dyes with chromatin. Such characteristics include peripheral localization of chromatin, its condensation and cell fragmentation into membranebound apoptotic bodies (Fig. 3).

\section{Results and discussion}

Treatment of old Balb/c mice with CNs for three days once a day (at a dose of $45 \mathrm{mg} / \mathrm{kg}$ ) led to a positive effect on reproductive system. The number of living granulosa cells increased from $33.08 \pm 0.19 \%$ to $73.25 \pm 0.86 \%$ (Fig. 4), while percentage of the necrotic and apoptotic ones decreased relative to control (corresponding data are $0.50 \pm 0.23 \%$ and $26.25 \pm 0.92 \%$ vs. $12.58 \pm 0.60$ and $54.33 \pm 0.92 \%$ in control group; $\mathrm{P}<0.01)$. The number of oocytes in follicles also increases from $13.00 \pm 1.96 \%$

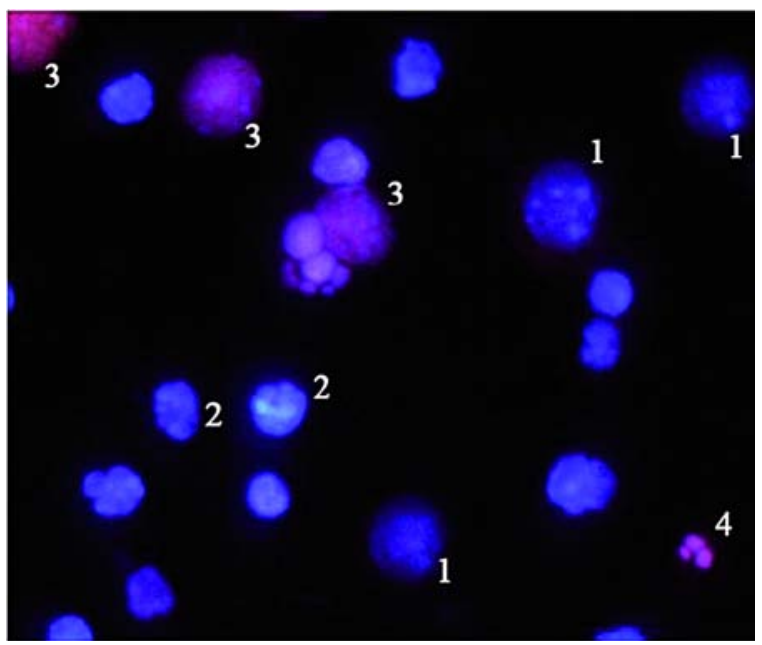

Fig. 3 Fluorescent microscope image of follicular cells stained with fluorescent dyes Hoechst 33342 and propidium iodide: 1-viable cells (Hoechst 33342 penetrates non-injured membranes and stains the nuclei of live cells in blue); 2-apoptotic cells (with characteristic nuclear changes: chromatin condensation, nuclear fragmentation, apoptotic bodies);3-necrotic cells (propidium iodide penetrates through leaky plasma membranes and stains their nuclei in red); 4-apoptotic bodies.

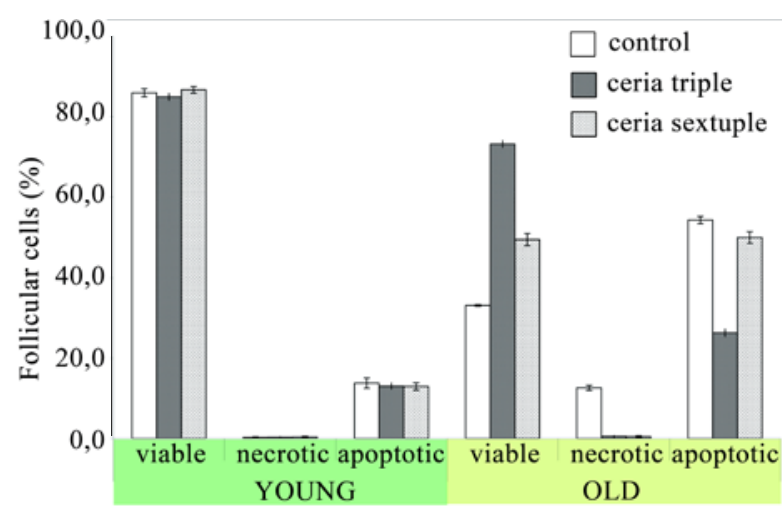

Fig. 4 The percentage of viable, apoptotic and necrotic follicular cells to the total amount of cells was calculated (mean \pm SD) in young and old $\mathrm{Balb} / \mathrm{c}$ mice treated with CNs. The follicular cells were examined not later than two hours after their mechanical separation from the cumulusoocyte cellular complexes. In each treatment group were investigation 5-6 animals. Control mice received sodium citrate solution $(0.03 \mathrm{M})$. For each animal not less than 1200 follicular cells were examined. 


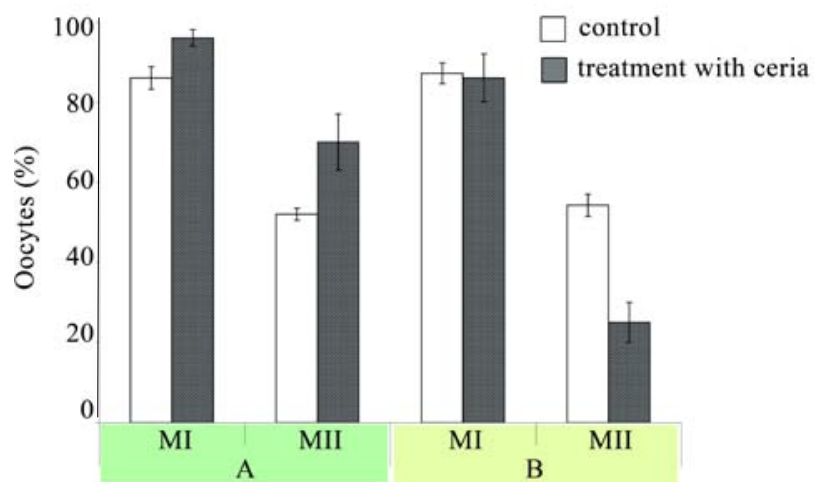

Fig. 5 The percentage of oocytes (mean \pm SD) with germinal vesicle breakdown (metaphase I) and oocytes forming the first polar body (metaphase II) in old Balb/c mice treated with CNs. A: triple treatment of mice with $\mathrm{CNs}$; B: sextuple treatment of mice with CNs. Control mice received sodium citrate solution $(0.03 \mathrm{M})$. The oocytes (in cumulus-oocyte complexes) were cultured in medium in a humidified $5 \% \mathrm{CO}_{2}$ atmosphere at $37{ }^{\circ} \mathrm{C}$ for 4 and $20 \mathrm{~h}$. The number of metaphase I oocytes was counted after $4 \mathrm{~h}$, while the number of metaphase II oocytes was estimated by optical microscopy after 20 $\mathrm{h}$ of culture. The total number of examined oocytes were 425:138 oocytes from control mice and 287-from mice treated with CNs.

to $9.00 \pm 1.76 ; \mathrm{P}<0.05$. This effect is accompanied by an increased in the number of oocytes at metaphase I and metaphase II (corresponding data are 96.60 $\pm 1.88 \%$ and $70.00 \pm 7.39 \%$ vs. $86.27 \pm 2.80 \%$ and $51.81 \pm 1.54 \%$ in control group; $\mathrm{P}<0.05$ ) (Fig. 5).

In case of young Balb/c animals, however, triple treatment with CNs (at the same dose) did not lead to significant changes in the number of oocytes inside follicles or percentage of cells that successfully reached metaphase I and II $(85.71 \pm 2.58 \%$ and $50.55 \pm 5.72 \%$ relative to $86.71 \pm 1.48 \%$ and $53.74 \pm 2.11 \%$ in control group; $\mathrm{P}>0.05$ ) (Fig. 6). In young mice, $\mathrm{CNs}$ affected neither viability of granulosa cells nor their inclination to undergo necrosis or apoptosis (respective data are $73.08 \pm 0.84 \% ; 0.25 \pm 0.13 \% ; 26.67 \pm 0.81 \%$ vs. $74.33 \pm 0.42 \% ; 0.33 \pm 0.14 \% ; 25.42 \pm 0.74 \%$ in control group; $\mathrm{P}>0.05)$.

Sextuple treatment of old females with $\mathrm{CNs}$ showed smaller antiapoptotic effect, than observed in case of triple treatment. The fraction of apoptotic granulosa cells was the same as in the control old animal group

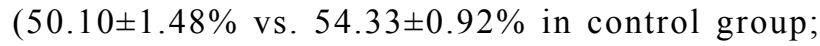
$\mathrm{P}>0.05)$. Corresponding result of triple treatment was significantly $(\mathrm{P}<0.01)$ greater than that of sextuple treatment and control. Due to reduction of antiapoptotic effect mean number of living cells decreased, however remaining higher than that of control $(49.50 \pm 1.47 \%$ vs. $33.08 \pm 0.19 \% ; \mathrm{P}<0.01)$, but significantly lower than in case of triple treatment (Fig. 4). At the same time reduction in the number of granulosa cells with morphological signs of necrosis was found only after six CNs administration (from $12.58 \pm 0.60 \%$ in control group to $0.42 \pm 0.26 \% ; \mathrm{P}<0.01$ ). Sextuple treatment with CNs did not change the number of metaphase I oocytes ( $86.40 \pm 5.80 \%$ vs. $87.16 \pm 2.58 \%$ in control group; $\mathrm{P}>0.05)$, but reduced the ability of oocytes to reach metaphase II

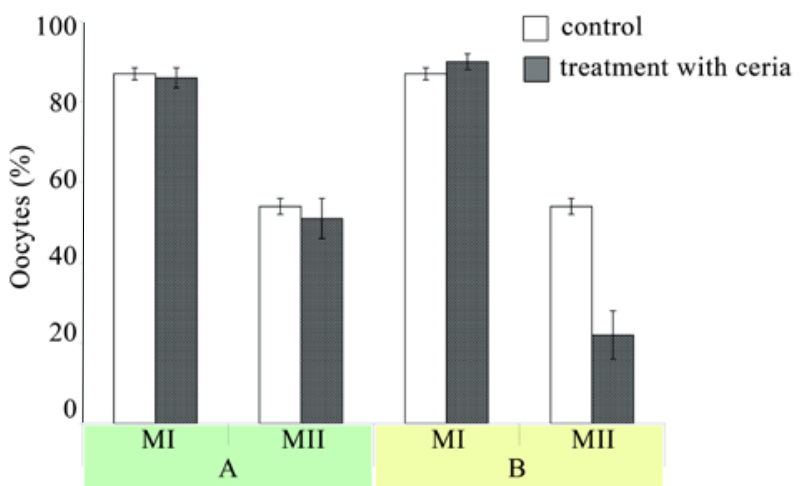

Fig. 6 The percentage of oocytes $(\operatorname{mean} \pm \mathrm{SD})$ with germinal vesicle breakdown (metaphase I) and oocytes forming the first polar body (metaphase II) in young Balb/c mice treated with CNs. A: triple treatment of mice with CNs; B: sextuple treatment of mice with CNs. Control mice received sodium citrate solution $(0.03 \mathrm{M})$. The oocytes (in cumulus-oocyte complexes) were cultured in medium in a humidified $5 \% \mathrm{CO}_{2}$ atmosphere at $37^{\circ} \mathrm{C}$ for 4 and $20 \mathrm{~h}$. The number of metaphase I oocytes was counted after $4 \mathrm{~h}$, while the number of metaphase II oocytes was estimated by optical microscopy after 20 $\mathrm{h}$ of culture. The total number of examined oocytes were 476: 155 oocytes from control mice and 321-from mice treated with CNs.

(respectively $24.97 \pm 5.07 \%$ and $54.23 \pm 2.76 \%, \mathrm{P}<0.01$ ) (Fig. 5).

Sextuple treatment of young Balb/c mice with CNs revealed similar tendency: oocyte ability to reach metaphase I was not altered $(90.49 \pm 1.96 \%$ vs. $86.71 \pm 1.48 \%$ in control group; $\mathrm{P}>0.05)$, however the number of oocytes at the metaphase II stage significantly reduced $(22.18 \pm 6.25 \%$ and $53.74 \pm 2.11 \%$, respectively; $\mathrm{P}<0.01$ ) (Fig. 6). Application of mentioned dosing regimen had no significant effect on the number of living, apoptotic or necrotic granulosa cells relatively to control $(86.75 \pm 0.83 ; 12.92 \pm 0.89 ; 0.33 \pm 0.19 \%$ vs. $86.00 \pm 1.00$; $13.75 \pm 1.27 ; 0.25 \pm 0.13 \%$ respectively; $\mathrm{P}>0.05$ ).

In order to confirm/disapprove described results, the experiments were conducted also on CBA line. Data obtained on CBA old mice provided additional evidence for a positive effect of $\mathrm{CNs}$ on granulosa cell viability: the number of living granulosa cells increased, while percentage of apoptotic ones declined relative to control (corresponding data are $57.89 \pm 3.00 \% ; 38.44 \pm 3.37 \%$ vs. $31.75 \pm 4.33 \%$; $64.25 \pm 5.14 \%$ in control group; $\mathrm{P}<0.01$ ). The number of oocytes in follicles also increased ( $2.00 \pm 0.50$ compared to $0.50 \pm 0.30$ in control group; $\mathrm{P}<0,05)$.

It was revealed, that obtained litter size is proportional to active oocytes at the metaphase II stage; the viability and behavioural indicators of neonatal mice in the treated group did not differ from the control.

In a healthy organism reactions of free radical production and their inactivation are balanced. Disruption of this balance due to enhanced ROS formation or impaired mechanisms of antioxidant production results in oxidative stress. Oxidative stress affects duration of female reproductive period, even during menopause. The nature of ROS action upon female reproductive system is 
dual: serving as a key signal molecules in physiological processes, reactive oxygen species are also involved in pathogenesis of various reproductive disorders $[15,16]$. ROS affect numerous physiological processes: meiotic maturation of oocytes, follicular development, and ovulation, cyclic changes in endometrium, fertilization, embryo growth and pregnancy [17-19].

In particular, redox status of the cell modulates angiogenesis, which is crucial for follicular growth, corpus luteum formation, endometrium differentiation and embryonic growth. There are reasons to believe that oxidative stress modulates age-related decrease in fertility. Oxidative stress also plays a role during pregnancy and normal parturition and in initiation of preterm labor [16]. Numerous studies have shown that oxidative stress is involved in pathophysiology of preeclampsia, free radical induced birth defects and abortion stimulation. Oxidative stress also plays a role in the pathophysiology of infertility and negative outcomes after in vitro fertilization, in pathogenesis of tubo-peritoneal factors infertility, endometriosis development, as well as unexplained infertility $[15,16]$.

It has been shown that ROS generation in culture medium, which is used for assisted reproductive techniques, is greater than such in follicular fluid, which damages oocyte plasma membrane [20]. ROS can damage gametes and therefore embryos through DNA and RNA fragmentation, membrane lipid peroxidation [21]. This provides reasons for modifying in vitro fertilization protocols with the purpose to reduce ROS generation.

In view of cerium dioxide antioxidant properties, improvements in oocyte meiotic maturation, as well as viability of granulosa and cumulus cells after triple treatment with $\mathrm{CNs}$ can be explained by normalized balance between free radical production and system of their inactivation. Complex interactions between oxidative stress and cytokines that are involved in etiology of female reproductive system diseases should also be taken into account. Free radicals induce lipid peroxidation and cytokine secretion, including tumor necrosis factor-alpha
[22] increased concentration of which, as was previously shown [23], inhibits oocyte meiotic maturation and reduces number of living cumulus and granulosa cells via promotion of apoptotic and necrotic death.

However prolongation of treatment with $\mathrm{CNs}$ canceled positive changes in condition of cumulus-oocyte complexes. Such an effect can be explained using data concerning effect of antioxidants upon murine ovaries. According to Skolnik at al [24], ovulatory process can be down-regulated by ROS, which, in turn, are targeted by antioxidants. Apparently, ROS are formed in response to luteinizing hormone and serve as physiological intermediates of ovulation. It is important to note that antioxidants inhibit cumulus expansion, which roughly coincides with meiotic maturation [25].

Oocyte maturation and cumulus development are interrelated [26,27]. Optimal expansion of the cumulus mass is essential for cytoplasmic oocyte maturation [28]. It is generally known that oocyte maturation includes both nuclear and cytoplasmic maturation. The poor developmental competence of oocytes can be caused by insufficient cytoplasmic maturation, even if nuclear maturation is normal [29-32]. Thus, disorders in cumulus expansion can negatively affect oocyte maturation. As a result, the number of mature eggs leaving follicles decreases dramatically [23]. Usually, the deficiency of cytoplasmic maturation during in vitro fertilization results in impaired ability of oocyte to form male pronucleus and to develop into blastocysta $[33,34]$.

\section{Conclusion}

Growing evidences report that oxidative stress increases with aging of the organism. It is connected with intensification of the oxidant generation or/and weakening of the antioxidant system. As a result, more oxidants are present in the aged organism, which, in particular, leads to the loss of reproductive potential. Reactive oxygen species (ROS) can modulate cellular functions, and oxidative stress (OS) can impair the intracellular milieu, resulting in diseased or dead cells. As in many

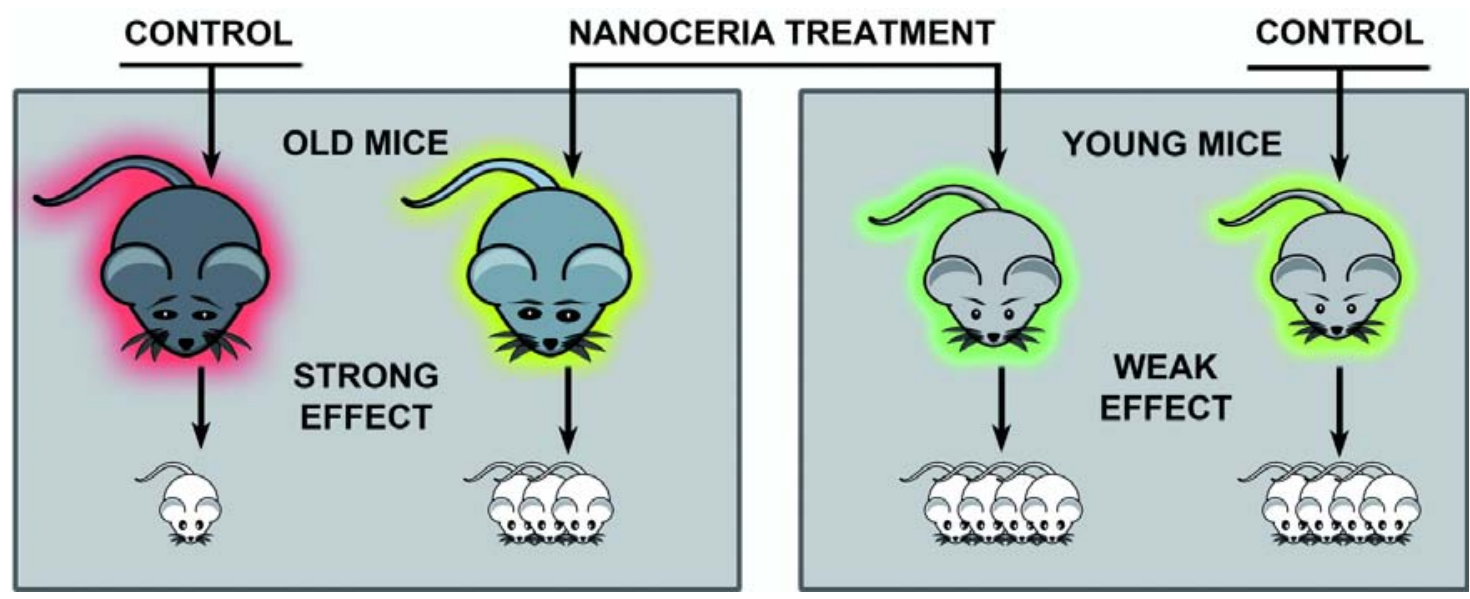

Fig. 7 The schematic conclusion of the article. NCs protect ovarian cells of old mice against oxidative damage thus working as anti-ageing agent. Treatment with NCs results in increase in the number of oocytes in follicles, increase in the number of oocytes at metaphase I and metaphase II, increase in the number of living granulosa cells and decrease in the number of necrotic and apoptotic cells. 
cellular processes, a low level of ROS synthesis plays an important role in cell signal transduction pathways; in the oocyte, it is a prerequisite for the first meiotic phase (MI) and is also required for folliculogenesis. However, excessive ROS synthesis will impair oocyte maturation, and an inadequate intracellular antioxidant capacity (in particular, low concentrations of reduced glutathione) can limit successful ovulation and fertilization. In vitro fertilization is also affected by excessive ROS in embryo culture media, and the routine practice of incubating embryos at low oxygen pressure can prevent embryo arrest and enhance the chances of successful fertilization [35].

Reproductive cells and tissues remain stable when free radical production and scavenging by antioxidants remain in balance. ROS can affect a variety of physiological functions in the reproductive tract, and its excessive level can result in precipitous pathologies affecting female reproduction. The oxidant status can influence early embryo development by modifying the key transcription factors, hence modifying gene expression [36]. Nuclear and cytoplasmic failure of the aged oocyte can exert a negative influence on its developmental competence of oocyte [37].

The state of arrested meiosis is normal for oocytes. MI is a key step to exit the state of arrest. A sharp reduction in percentage of oocytes that spontaneously resume meiosis is detected in old animals. Average levels of ROS can activate oocytes and the development of subsequent phases of meiosis. The final stage of ovulation requires the abrupt changes in the level of ROS (which are the result of complex interactions of cytokines, hormones and other factors). It is possible that the administering of ceria leads to changes in the levels of ROS and these changes are the wake-up factor.

On the other hand, the success of global rearrangements in the oocyte cytoplasm and nucleus (destruction of the germinal vesicle, the formation of polar body) is determined by the degree of preservation of old transcripts. During the maturation of oocytes, some transcripts are destroyed rapidly and purposefully, while other transcripts must survive [38]. It is possible that CNs can affect them in some way, causing the effects we have found. CNs, as antioxidant agent, minimize concentration of free radicals down to the extent typical for young animals and required for the normal physiological processes. ROS depletion below normal levels can inhibit reproductive potency as well. Deterioration rates of reproductive system in young mice after sextuple treatments with ceria indicate their high sensitivity.

It is important that the study of the reproductive system requires a strict account of all factors such as age, linear background etc. Depending on the initial state of the reproductive system the measure of effectiveness of the ceria treatment will vary. In case of old mice nanocrystalline ceria protects ovarian cells against oxidative damage, working as anti-aging agent; the litter size in old mice treated with the CNs increases too (Fig. 7).

\section{Acknowledgements}

The authors would like to thank Dr. Sudipta Seal of the University of Central Florida for his kind assistance with HRTEM of examined ceria nanoparticles.

\section{References}

1 Jakupec M.A., Unfried P., Keppler B.K., Pharmacological properties of cerium compounds. Rev. Physiol. Biochem. Pharmacol. 2005;153:101-111.

2 Karakoti A.S., Monteiro-Riviere N.A., Aggarwal R., Davis J.P., Narayan R.J., Self W.T., Nanoceria as Antioxidant: Synthesis and Biomedical Applications. JOM 2008;60(3):33.

3 Ivanov V.K., Shcherbakov A.B., Usatenko A.V., Structure-sensitive properties and biomedical applications of nanodispersed cerium dioxide. Russ. Chem. Rev. 2009;78(9):855-71.

4 Celardo I., Pedersen J.Z., Travers E., Ghibelli L., Pharmacological potential of cerium oxide nanoparticles. Nanoscale 3(4):1411-21.

5 Shcherbakov A.B., Ivanov V.K., Zholobak N.M., Ivanova O.S., Krysanov EIu, Baranchikov A.E., Nanocrystaline ceria based materials-perspectives for biomedical application. Biofizika. 2011;56(6):995-1015.

6 Zholobak N.M., Ivanov V.K., Shcherbakov A.B., Shaporev A., Polezhaeva O.S., Baranchikov A.Y., UV-shielding property, photocatalytic activity and photocytotoxicity of ceria colloid solutions. J. Photochem. Photobiol. B. 2011;102:32-38.

7 Zholobak N., Shcherbakov A., Ivanov V., Olevinskaya Z., Spivak N., Antiviral effectivity of ceria colloid solutions. Antiviral Res. 2011; 90, 2:67.

8 Heckert E.G., Karakoti A.S., Seal S., Self W.T., The role of cerium redox state in the SOD mimetic activity of nanoceria. Biomaterials. 2008;29:2705-2709.

9 Schubert D., Dargusch R., Raitano J., Chan S.W., Cerium and yttrium oxide nanoparticles are neuroprotective. Biochem. Biophys. Res. Commun. 2006; 342:86-91.

10 Hirst S.M., Karakoti A., Singh S., Self W., Tyler R., Seal S., Biodistribution and In Vivo Antioxidant Effects of Cerium Oxide Nanoparticles in Mice. Environmental Toxicology. Published online in Wiley Online Library.

11 Kregel K.C., Zhang H.J., An integrated view of oxidative stress in aging: basic mechanisms, functional effects, and pathological considerations. Am J Physiol. Regul. Integr. Comp. Physiol. 2007;292(1):18-36.

12 Ivanov V.K., Polezhaeva O.S., Shaporev A.S., Baranchikov A.E., Shcherbakov A.B., Usatenko A.V., Synthesis and thermal stability of nanocrystalline ceria sols stabilized by citric and polyacrylic acid. Russ. J. Inorg. Chem. 2010;55(3):328-332.

13 Shimizu S., Eguchi Y., Kamiike W., Akao Y., Kosaka H., Hasegawa J., Involvement of ICE family proteases in apoptosis induced by reoxygenation of hypoxic hepatocytes. Am. J. Physiol. 1996;271:949-958.

14 Ciancio G., Pollack A., Taupier M.A., Block N.L., Irvin G.L, Measurement of cell-cycle phasespecific cell death using Hoechst 33342 and propidium iodide: preservation by ethanol fixation. J. Histochem. Cytochem. 1988;36(9):1147-1152.

15 Agarwal A., Saleh R.A., Bedaiwy M.A., Role of reactive oxygen species in the pathophysiology of human reproduction. Fertil. Steril. 2003;79(4):829-843.

16 Agarwal A., Gupta S., Sharma R.K., Role of oxidative stress in female reproduction. Reprod. Biol. Endocrinol. 2005;3:28

17 Behrman H.R., Kodaman P.H., Preston S.L., Gao S., Oxidative stress and the ovary. J. Soc. Gynecol. Investig. 2001;8:40-42.

18 Sabatini L., Wilson C., Lower A., Al-Shawaf T., Grudzinskas J.G., Superoxide dismutase activity in human follicular fluid after controlled ovarian hyperstimulation in women undergoing in vitro fertilization. Fertil. Steril. 1999;72:1027-1034.

19 Ishikawa M., Oxygen radicals-superoxide dismutase system and reproduction medicine. Nippon Sanka Fujinka Gakkai Zasshi. 1993;45:842-848. 
20 Martín-Romero F.J., Miguel-Lasobras E.M., Domínguez-Arroyo J.A., González-Carrera E., Alvarez I.S., Contribution of culture media to oxidative stress and its effect on human oocytes Reprod. Biomed. Online. 2008;17(5):652-61.

21 Ménézo Y., Guérin P., Gamete and embryo protection against oxidative stress during medically assisted reproduction. Bull. Acad. Natl. Med. 2005;189(4):715-26.

22 Lu C., Koppenol W.H., Inhibition of the Fenton reaction by nitrogen monoxide. J. Biol. Inorg. Chem. 2005; 10:732-738.

23 Voznesenska T.Yu, Blashkiv T.V., Shepel O.A., Yanchiy R.I., Experimental aspects of disturbances of reproductive function. Kyiv: Milanik. 2010, 184

24 Shkolnik K., Tadmor A., Ben-Dor S., Nevo N., Galiani D., Dekel N., Reactive oxygen species are indispensable in ovulation. Proc. Natl. Acad. Sci. USA. 2011;108(4):1462-1467.

25 Eppig J.J., Role of serum in FSH stimulated cumulus expansion by mouse oocyte-cumulus cell complexes in vitro. Biol. Reprod. 1980;22(3):629-633.

26 Ma S., Lin H., Miao Y., Liu X., Wang B., Dai J., The effect of three-dimensional demineralized bone matrix on in vitro cumulus-free oocyte maturation. Biomat. 2007;28:3198-3207.

27 Voznesenskaia TIu, Blashkiv T.V., Portnichenko A.G., Effect of cumulus and granulosa cells on meiosis resumption in murine oocytes in vitro. Tsitologiia. 2001;43(3):250-253.

28 Dell'Aquila M.E., Caillaud M., Maritato F., Martoriati A., Gérard N., Aiudi G., Cumulus expansion, nuclear maturation and connexin, cyclooxygenase- 2 and FSH receptor mRNA expression in equine cumulus-oocyte complexes cultured in vitro in the presence of FSH and precursors for hyaluronic acid synthesis. Reprod. Biol. Endocrinol. 2004;22:44.

29 Marchal R., Caillaud M., Martoriati A., Gerard N., Mermillod P. Goudet G., Effect of growth hormone $(\mathrm{GH})$ on in vitro nuclear and cytoplasmic oocyte maturation, cumulus expansion, hyaluronan synthases, and connexins and expression, and GH receptor messenger RNA expression in equine and porcine species. Biol. Reprod. 2003;69:1013-1022.
30 Ka H.H., Sawai K., Wang W.H., Im K.S., Niwa K., Amino acids in maturation medium and presence of cumulus cells at fertilization promote male pronuclear formation in porcine oocytes matured and penetrated in vitro. Biol. Reprod. 1997;57:1478-1483.

31 Yamauchi N., Nagai T., Male pronuclear formation in denuded porcine oocytes after in vitro maturation in the presence of cysteamine. Biol. Reprod. 1999;61:823-833.

32 Marchal R., Tomanek M., Terqui M., Mermillod P., Effects of cell cycle dependent kinases inhibitor on nuclear and cytoplasmic maturation of porcine oocytes. Mol. Reprod. Dev. 2001;60:65-73.

33 Tatemoto H., Muto N., Sunagawa I., Shinjo A., Nakada T., Protection of porcine oocytes against cell damage caused by oxidative stress during in vitro maturation: role of superoxide dismutase activity in porcine follicular fluid. Biol. Reprod. 2004;71(4):1150-1157.

34 Niwa K., Effectiveness of in vitro maturation and in vitro fertilization techniques in pig.J. Reprod. Fertil. 1993;48:49-59.

35 Ruder E.H., Hartman T.J., Blumberg J., Goldman M.B., Oxidative stress and antioxidants: exposure and impact on female fertility. Hum. Reprod. Update. 2008;14:345-37.

36 Sekhon L.H., Gupta S., Kim Y., Agarwal A., Female Infertility and Antioxidants. Curr. Womens Health Rev. 2010;6: 84-95.

37 Tantone C., Oocyte senescence: A firm link to age-related female. Gynecol. Endocrinol. 2008;24(2):59-63.

38 Su Y.Q., Sugiura K., Woo Y., Wigglesworth K., Kamdar S., Affourtit J., Selective degradation of transcripts during meiotic maturation of mouse oocytes. Dev. Biol. 2007;302(1): 104-117.

Copyright:(c) 2012 NYa Spivak et al. This is an open-access article distributed under the terms of the Creative Commons Attribution License, which permits unrestricted use, distribution, and reproduction in any medium, provided the original author and source are credited. 